\title{
Bicycle-Transit Integration in the United States, 2001-2009
}

\author{
Rui Wang and Chen Liu \\ UCLA Luskin School of Public Affairs
}

\begin{abstract}
This paper analyzes the recent trend in bicycle-transit integration in the U.S. It reviews data from the National Household Travel Surveys (NHTS) to show the characteristics of bicycle-transit integrated trips, where the integrators were from, and to which population groups the integrators belonged. Bicycle-transit integration was increasingly observed in commuters and younger travelers, and became more imbalanced by gender. Results indicate the rise in socio-economic diversity of bicycle-transit integrators, despite a racial gap. There was a clear concentration of bicycle-transit integrators in large and high-density urban areas, where most transit users lived. Evidence does not support that rail attracts more bike access/egress trips than bus. More transit users used bicycles to access/egress in the Pacific, East North Central, and Mountain regions. Given the non-trivial role of bicycles compared to transit in the U.S., the focus on bicycle use and the marriage between bicycle and transit should be further emphasized.
\end{abstract}

\section{Introduction}

As concerns about the efficiency of public transit, public health, energy supply, and climate change have risen in recent decades, U.S. policy makers have shifted from a highway-centric framework to a multimodal transportation system, which encourages the use of public transit and, increasingly, non-motorized modes. However, both transit and non-motorized modes provide limited mobility and accessibility to users. The maximum feasible travel distance of bicycling makes wide use of this 
mode impossible in U.S. cities, which have been designed largely for automobiles. Transit can reach a much longer distance, but transit services cannot stretch to every corner of an urban area. Therefore, current shares of bicycle and transit trips in U.S. cities are quite low compared to many foreign cities in the developed world.

Foreign experience has shown that the benefits of bicycle and transit travel are greater when combined (e.g., Replogle 1984, 1992). Since 53 percent of all people nationwide live less than 2 miles from the closest transit facility and 2 miles is likely accepted as a feasible riding distance by most cyclists, there is great potential for bicycle-transit integration to increase bicycle and transit use (FHWA 1994). The private and social benefits of bicycle-transit integration include increasing transit ridership by enlarging transit's catchment area (through solving the first/last-mile problem), improving cyclists' mobility by overcoming distance, topographical, weather, safety, and infrastructure barriers, lowering the necessary investment in park-and-ride facilities, and reducing air pollution and traffic congestion (TRB 1994, 2005).

The federal Intermodal Surface Transportation Efficiency Act (ISTEA) of 1991 and the subsequent Transportation Equity Act for the 21st Century (TEA-21) of 1998 enabled many state and local authorities to conduct planning studies, programs, and projects linking bicycles and transit in the 1990s. TEA-21 further encouraged bicycle-transit integration by allowing the federal share of transit enhancement grants that link bicycles and transit to reach 95 percent, instead of the usual 80 percent for transit enhancement activities (FTA 1999). As a result, since the 1990s, there has been significant growth in bicycle-transit integration in the U.S. In the early 1990s, bicycle- transit integration consisted mainly of bicycle parking. By the mid-2000s, a range of bicycle services (e.g., mounting bicycle racks on buses, allowing bicycles to board trains, installing bicycle racks and lockers at transit stations, and providing staffed bicycle parking facilities at major transit hubs) were offered by agencies of all sizes in many parts of the U.S. (TRB 2005).

This study provides one of the earliest evaluations of the status and trends of bicycle-transit integration in the U.S. Using the National Household Travel Surveys (NHTS) data, it describes the recent changes in using bicycles to access/egress transit and how the behavior of bicycle-transit integration relates to the characteristics of trips, geography, and travelers. Section Two of this paper reviews the existing literature, in particular empirical evidence, on bicycle-transit integration. Section Three describes data and methodology, followed by results and discussions presented in Section Four. Section Five concludes the paper with suggestions for policy makers and researchers. 


\section{Literature}

Perhaps due to the marginality of combining cycling and transit in North America, there is a shortage of reliable data and empirical studies on bicycle-transit integration (Bachand-Marleau et al. 2011). For example, as of 2005, few transit agencies had collected detailed data about bicycle-on-transit rider characteristics or bicycle parking use (TRB 2005). Hindered by the lack of boarding counts, Hagelin (2005) was unable to provide a meaningful cost-benefit analysis of bike-on-bus programs in Florida. Most of the existing empirical analyses on bicycle-transit integration are descriptive and use data from Western Europe (Givoni and Rietveld 2007; Martens 2004, 2007; Pucher and Buehler 2009, 2012; Rietveld 2000).

Martens $(2004,2007)$ examined the bicycle-transit integration experiences of European countries and cities, including places with relatively high shares (27\% in the Netherlands and 26\% in Copenhagen), medium shares (13\% in Munich), and low shares ( $2 \%$ in the UK) of bicycles in transit access. The majority of bike-andride trips were made for commuting purposes (work and education). Most users traveled under six kilometers to a public transit stop, with longer access distances reported for faster transit modes. Across all locations, except the UK, regional transit (e.g., train, suburban rail, and express bus) had higher shares of bicycle access than local transit (e.g., city bus, metro rail). For Dutch rail transit riders, bicycle use for transit access/egress decreased with the level of urbanization-highest in suburban areas, followed by medium-sized cities and large towns, and lowest in main cities. In addition, there was an imbalance between Dutch transit riders' home- and activity-end shares of bicycle use. For work, education, and shopping transit trips, bicycle use at the home-end was much higher than at the activity-end. Also, Martens found that choosing to use a combination of bicycle and train did not seem to be associated with the availability of a car, but car availability was clearly correlated with the levels of bike-and-ride for slower modes of transit.

Givoni and Rietveld (2007) found that most of the surveyed Dutch rail passengers chose walking, bicycling, and public transport to get to or from rail stations. From 1978 to 2005, walking, cycling, and transit dominated access to home-end rail stations, while walking and transit dominated access at the activity-end rail stations. Similar to Martens (2004), they found that the availability of a car did not correlate with the mode choice to access the stations. The bicycle was used much more often at the home-end than at the activity-end for transit access/egress, while the opposite held for walking and transit. Walking and bicycling were both used more often for station access distances under, rather than above, three kilometers. 
By compiling data from 150 on-board vehicle passenger survey datasets (more than 496,000 public transit riders sampled in total) conducted by public transportation agencies from 2000 to 2005, the American Public Transportation Association (APTA 2007) found that the primary means of transit access and egress was walking (59.6\% for access and $63.8 \%$ for egress). The second most common mode of public transit access and egress was transferring from another transit vehicle, accounting for 17.2 percent and 21.6 percent of access and egress trips, respectively. Automobiles and other private vehicles accounted for 21.0 percent and 12.0 percent of access and egress trips, respectively. The bicycle was combined in the "other access/ egress modes" group, totaling 2.2 percent and 2.6 percent of access and egress, respectively. These results are consistent with the Transit Performance Monitoring System (TPMS) reports, the other major U.S. source on transit access and egress. Data from 58 surveys conducted from 1996 to 2003 suggest that the dominant access/egress modes were walking, transit, and automobile. On the other hand, the bicycle was combined in the "other access/egress modes" group, totaling 0.6-1.3 percent of access and 1.1-1.5 percent of egress (APTA 2007).

Only a small number of studies provide more in-depth analysis of bicycle-transit integration behavior. Using a nested logit model, Debrezion et al. (2009) studied the joint access mode and railway station choices of Dutch railway users. They found a steeper negative distance effect on the utility of accessing departure stations by walking and bicycle, compared to car and public transport. Availability of parking spaces and bicycle standing areas had a positive effect on the choice of accessing departure railway stations by car and bicycle. Through analyzing access to railway stations' effect on rail use, Brons et al. (2009) found that in Dutch cities, improving the infrastructure network for access and expanding access services to the railway station can substitute for improving and expanding the services provided in the rail network, and were probably more cost effective for increasing rail use.

Bachand-Marleau et al. (2011) analyzed online survey data to identify current or potential groups of bicycle-transit integrators in the region of Montreal, Canada. Bringing a bicycle on transit was the preferred form of integration by the survey respondents, although they were likely to use bicycle parking or a public bicycle more regularly. Using on-board survey data, Bergman et al. (2011) analyzed the access mode choice by riders of the newly-constructed Westside Express Service (WES), a suburb-to-suburb commuter rail in the Portland, Oregon, metropolitan area. They found the importance of pro-sustainability attitudes in choosing bike access and strong access mode choice effects of feeder bus lines and parking provi- 
sion in station area. Assessing the costs and cyclists' preferences of four common bicycle and transit integration strategies (i.e., bike on transit, bike to transit, two bike-one for access and one for egress-and shared bike) in five communities, Krizek and Stonebraker (2011) suggested that cyclists mostly preferred transit with bicycles aboard but the growth potential of bike on transit was limited. Enhancing bicycle parking at transit stops proved most cost-effective, although security was an important concern for cyclists.

In general, it seems that in-depth and rigorous analysis of bicycle-transit integration in the U.S. needs more reliable empirical evidence. Furthermore, almost all of the statistics on bicycle-transit integration reported in the existing literature are not accompanied with standard errors. Due to the small mode shares of transit and bicycle (not to mention the share of bicycle-transit integrated trips) and the limited sample sizes in most analyses, omitting standard errors is extremely problematic.

\section{Research Design}

To describe patterns and progress in bicycle-transit integration in the U.S., this study relies mainly on the recent NHTS in 2001 (Version 4.0, July 2005) and 2009 (Version 2.1, February 2011), which provide detailed information on the access/ egress modes of transit riders. Information from earlier national travel surveys in 1983, 1990, and 1995 were used to provide a longer time series of trends in transit and bicycle usage. Total number of day trip observations increased from 45.3 thousand in 1983 to 149.5 thousand in 1990, 409 thousand in 1995, 642.3 thousand in 2001, and 1.17 million in 2009.

We focus on the surveys' day trip data, which were collected in a 24-hour period. The purposes (types) of trips include home-based work (HBW), home-based shopping (HBS), home-based social/recreational (HBSR), other home-based (OHB), and not home-based (NHB). This study analyzes the most commonly-used transit: local public transit buses, commuter buses, commuter train, subway/metro rail, and streetcar/trolley. Other public transportation modes such as school/charter/tour/ intercity bus, hotel/airport shuttle, taxi, Amtrak, airplane, or passenger line/ferry are excluded from this analysis unless otherwise specified.

All reported statistics are weighted using household level weights adjusted for nonresponse in the datasets. Whenever possible, statistical variances are calculated and 95 percent confidence intervals $(\mathrm{Cl})$ are reported using jackknife replicate weights. 


\section{Results}

\section{Overall Pattern and Trend of Transit and Bicycle Usage}

Figure 1 presents the general picture of transit and bicycle usage over the past three decades. Among the day trips with mode reported (more than $99.9 \%$ of trips in each survey), overall transit mode share decreased steadily from 2.3 percent in 1983 to 1.6 percent in 2001, but bounced back to 1.9 percent in 2009, slightly below the 1990s level. When expanding the definition of transit from local and commuter public buses and (sub)urban rail to include school bus, charter/tour bus, shuttle bus, Amtrak, and airplane, the transit mode split more than doubles to 5.2 percent in 1983, 4.7 percent in 1990, 4.1 percent in 1995, 3.6 percent in 2001, and 4.6 percent in 2009, while the overall trend remains the same. Based on the narrow definition of transit, transit trips have been dominated by bus (mode shares of $64-75 \%$ ), subway (14-29\%), and commuter rail (5-10\%) during 1983-2009. The trend in bus mode share follows that of transit overall, while the aggregate share of rail modes (commuter, metro, and light rail) was fairly stable over time.

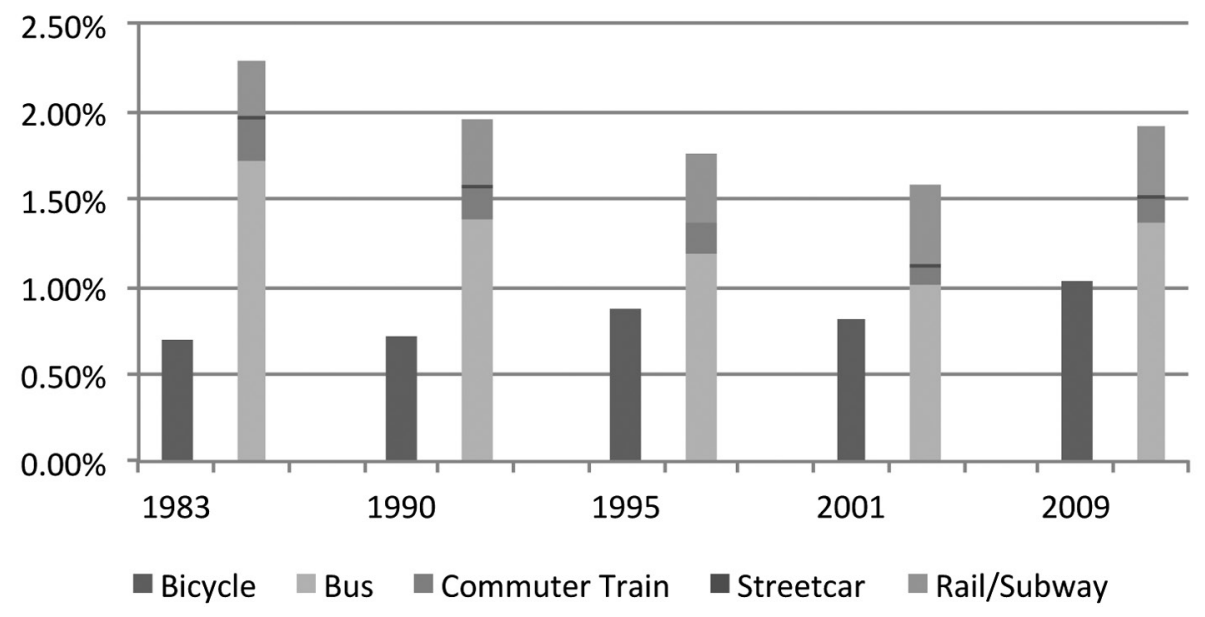

Figure 1. Bicycle and transit usage trend

The detailed access and egress of transit trips were only reported in the recent two NHTS surveys. Figure 2 presents the mode shares of access/egress to transit trips by trip type. Transit access/egress was dominated by walking for all trip purposes, but slightly less so for home-based work (HBW) trips and more so for home-based shopping (HBS) trips. ${ }^{1}$ Bicycle use for transit access/egress was close to 0 percent ( $95 \%$ Cl: $0.02-0.3 \%)$ in 2001, but rose to 0.6 percent (95\% Cl: $0.3-0.8 \%)$ in 2009. 


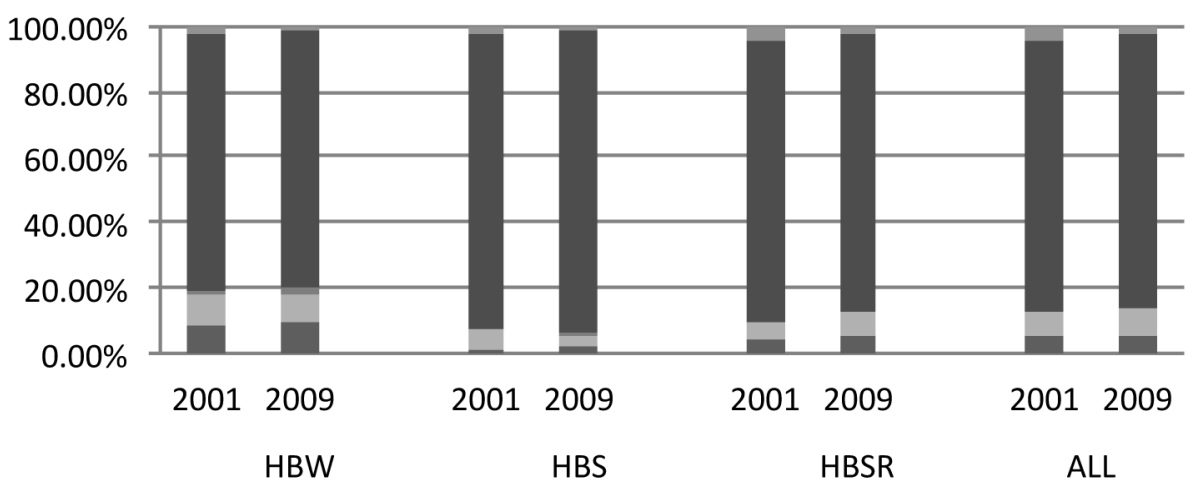

Private Vehicle Public Transportation Bicycle $\square$ Walk Other Modes

\section{Figure 2. Transit access/egress mode split in 2001 and 2009 by trip type}

The trend for bicycle usage, however, differs from that of transit. Bicycle mode share increased slowly from 0.7 percent in 1983 to 1 percent in 2009, with a small decrease from 1995 to 2001. An obvious but often neglected observation is that the bicycle mode is not a trivial mode compared to transit (even with its expanded definition). Bicycle mode share grew from 31 percent of transit (narrowly defined) mode share in 1983 to 54 percent by 2009 .

\section{The Uneven but Changing Picture of Bicycle-Transit Integration}

Two types of statistics were used to interpret bicycle-transit integrated travel behavior in the NHTS data. The first statistic is the share of bicycle-transit integrated trips in different, mutually exclusive, but together exhaustive categories, reflecting the distribution of the number of bicycle-transit integrated trips. The second is the mode share of bicycle in transit access/egress across categories, showing how the role of bicycle in transit access/egress varies by trip, geographical, and traveler characteristics. Combined with the distribution of transit trips across categories, the second statistic can often explain the pattern changes of the first statistic.

\section{Variations by Trip Characteristics}

From 2001 to 2009, the average bicycle-transit integrated trip became longer (both overall and access/egress distances). The mean total trip distance of bicycle-transit integrated trips increased from 10.7 miles in 2001 to 16.7 miles in 2009, accompanied by a rise in the average time of bike access/egress to transit from 8.8 to 11.9 minutes.

There are two notable changes in transit-bicycle integration in terms of trip characteristics. The first is the increased importance of commute trips. In 2001, there 
was no statistically significant difference in the share of bicycle-transit integrated trips by trip type. However, in 2009 it became clear that HBW trips were the most important trip purpose, as shown by the proportions and 95 percent $\mathrm{Cl}$ in Figure 3. In 2009, bicycle mode share in transit access/egress was also higher for HBW transit trips than HBS and HBSC transit trips, as shown in Figure 4. However, even for 2009 HBW transit trips, the 95 percent $\mathrm{Cl}$ of bicycle's share in access/egress was below 4 percent. For most trip types, bicycle mode share in transit access/egress did not show a statistically significant increase over time. The only exception was a marginally significant increase in HBW trips from nearly zero in 2001 to 1.3 percent (95\% Cl: $0.8-2.4 \%$ ) in 2009, which seems to be the main contributor to increased bicycle use for transit access/egress in Figure 2.

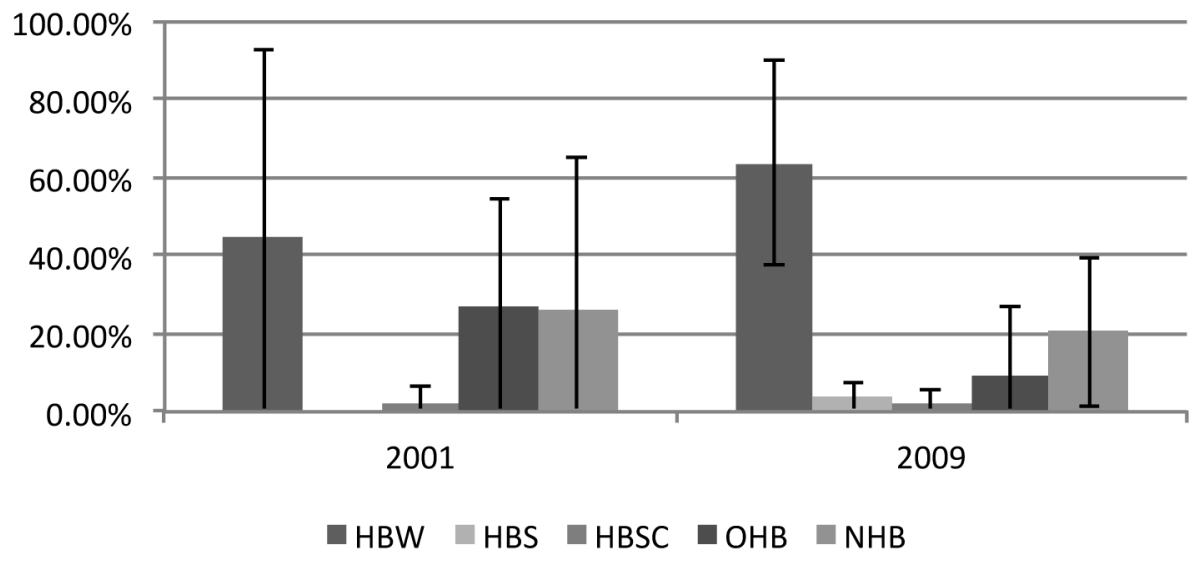

Figure 3. Shares of bicycle-transit integrated trips by trip type

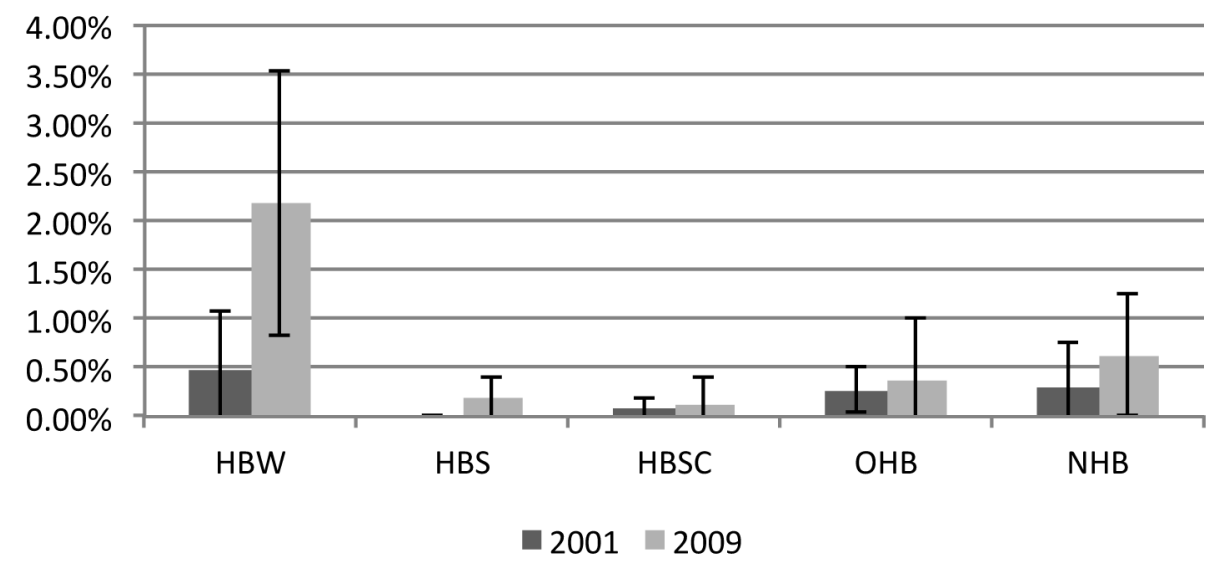

Figure 4. Bicycle's share in transit access/egress by trip type 
Secondly, in 2009, more bicycle-transit integrators used the bus than the subway or streetcar, and there were fewer integrated trips by subway than by bus or commuter train, as shown in Figure 5. However, the bicycle mode shares for the access/ egress of different types of transit were statistically indistinguishable (Figure 6). Under no transit mode or year could the bicycle mode share in access/egress be considered higher than 7 percent, based on 95 percent $\mathrm{Cl}$ estimates. Also, the mode share of bicycles in transit access/egress did not show a statistically significant increase over time for most transit mode categories, except a marginally significant increase for bus. Overall, the evidence is unsupportive for, if not against, the claim that the faster mode (rail) attracts more bike access/egress trips, a pattern found in Europe (Martens 2007). ${ }^{2}$

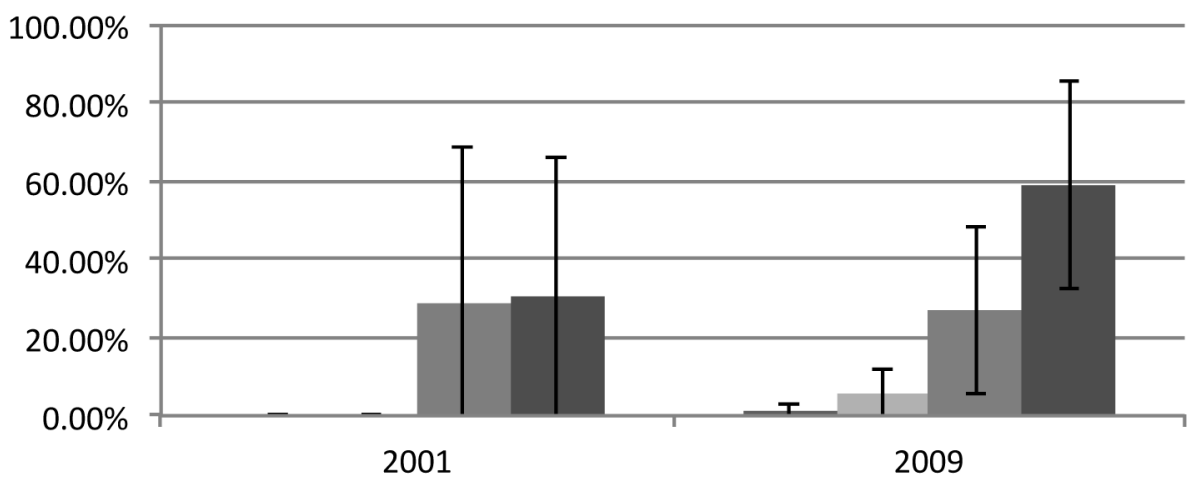

- Subway Streetcar $\square$ Commuter rail $\square$ Bus

Figure 5. Shares of bicycle-transit integrated trips by transit mode

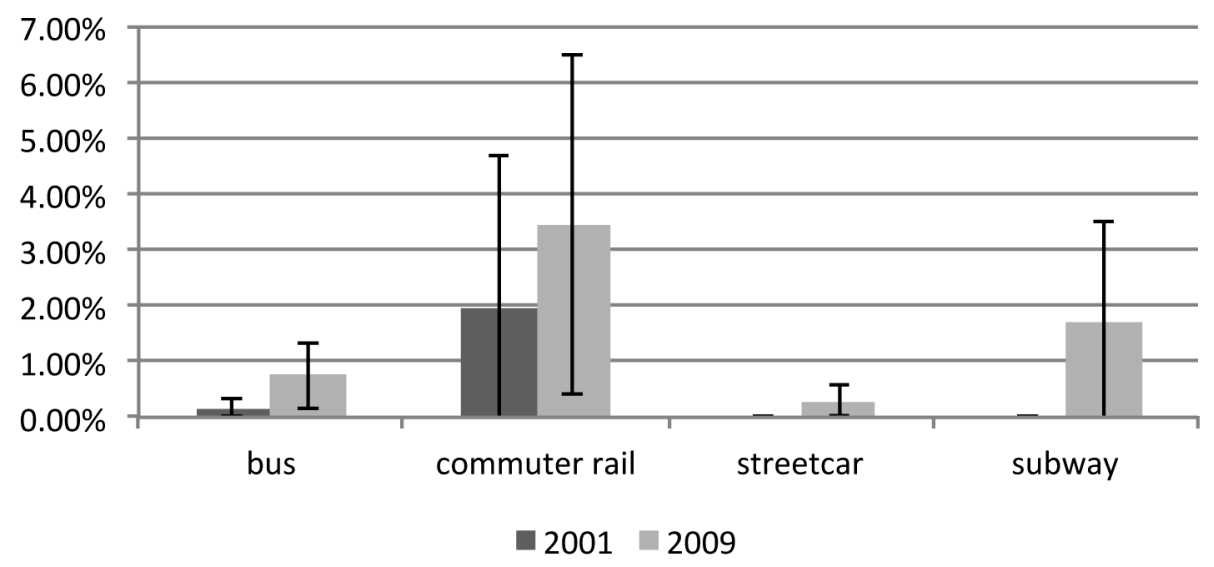

Figure 6. Bicycle's share in transit access/egress by transit mode 


\section{Geographical Variations}

It is well-known that different regions in the U.S. vary in their bicycle culture. As shown in Figure 7, in both 2001 and 2009, the Pacific region (Alaska, California, Hawaii, Oregon, and Washington) has more bicycle-transit integrators than all other regions, except East North Central (including Indiana, Illinois, Michigan, Ohio, and Wisconsin). However, among transit users, the shares of those who use bicycles to access/egress did not have a statistically significant difference among regions in 2001. In 2009, bicycle mode share in transit access/egress became significantly higher in the Pacific region than in all other regions, except the East North Central and Mountain (including Arizona, Colorado, Idaho, New Mexico, Montana, Utah, Nevada, and Wyoming) regions. Overall, results suggest that more transit riders used bicycles to access/egress in the Pacific, East North Central, and Mountain regions, but the absolute number of integrated trips was higher in the first two regions, probably due to their larger population sizes and/or higher public transit mode share.

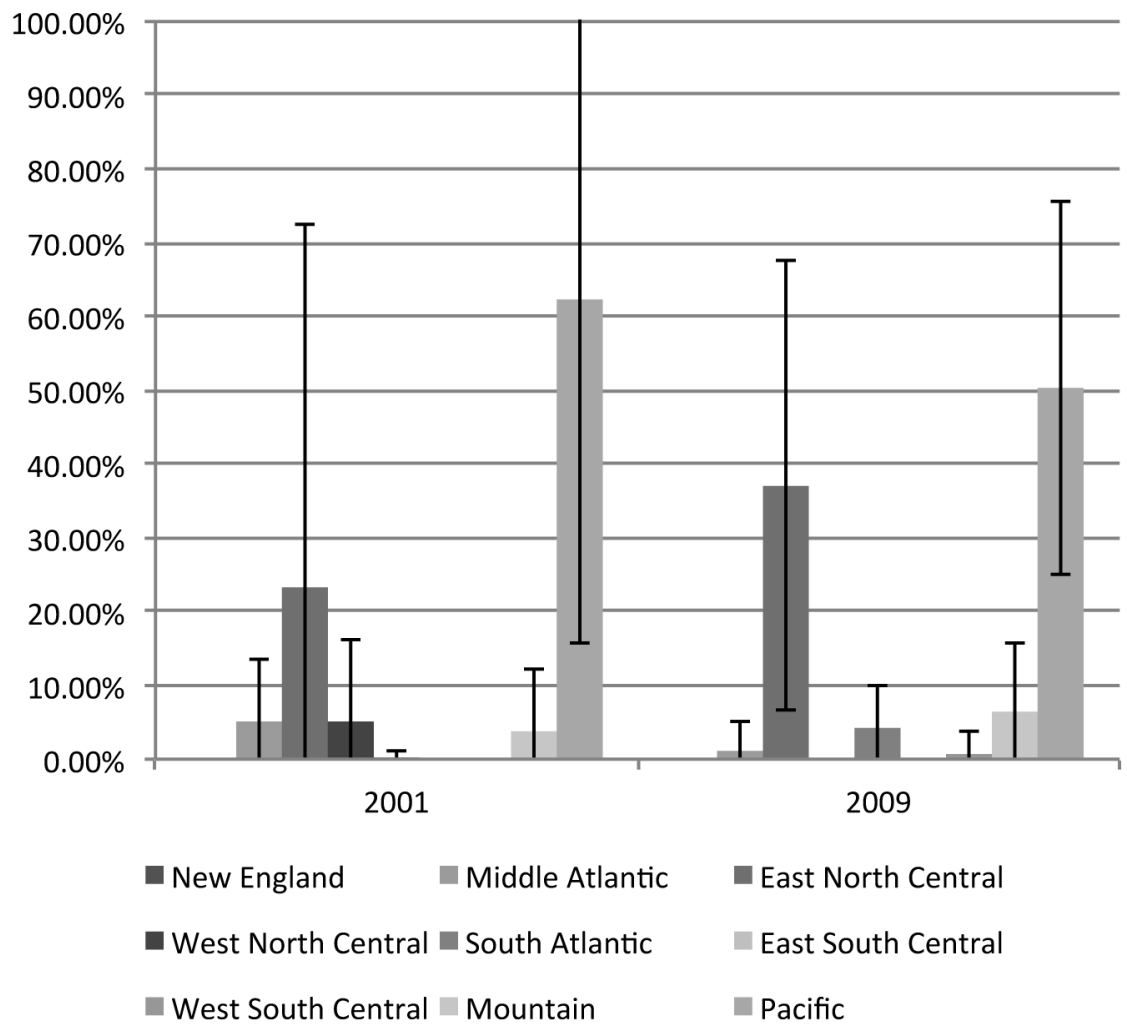

Figure 7. Shares of bicycle-transit integrated trips by division 


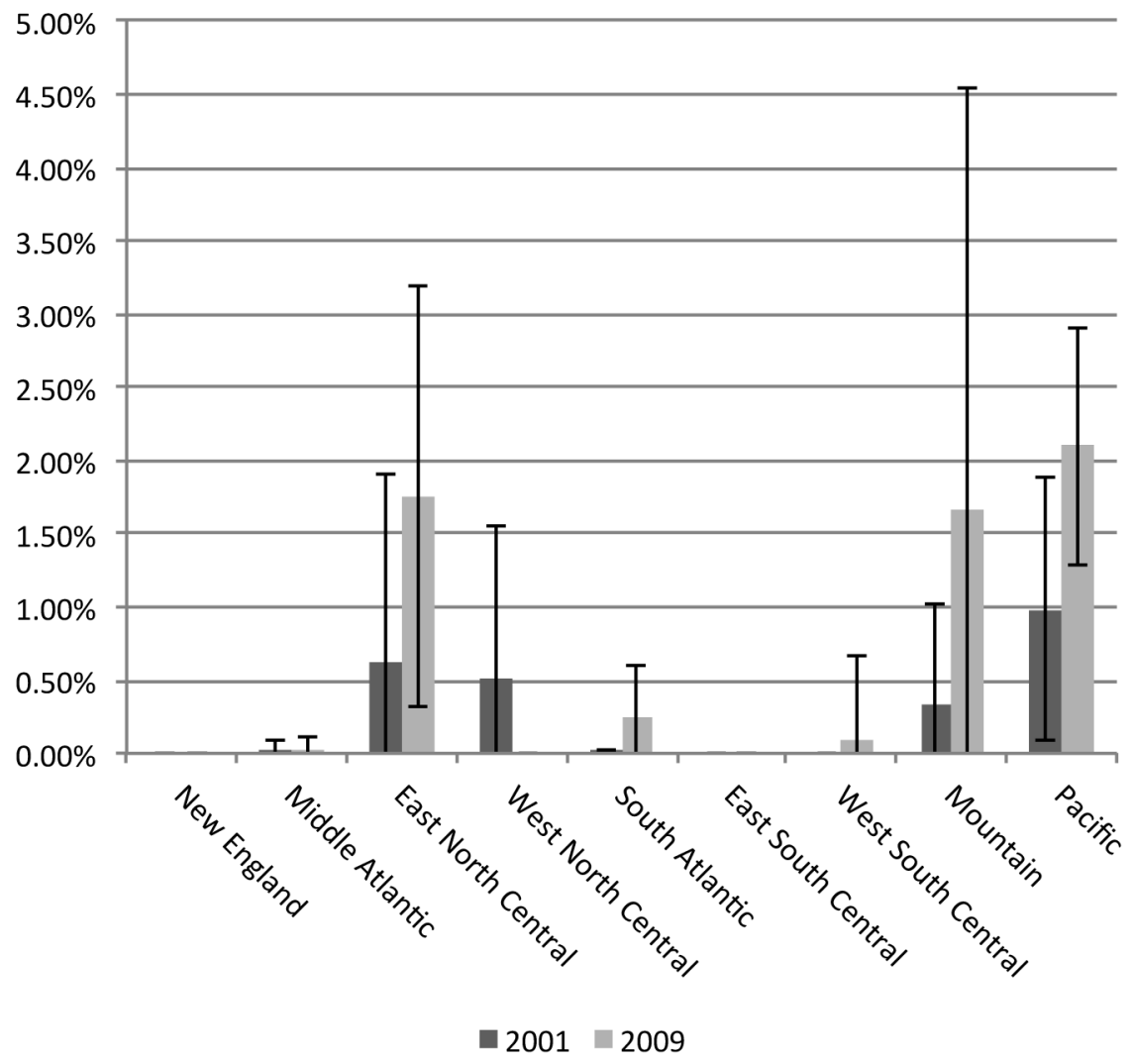

Figure 8. Bicycle's share in transit access/egress by division

As shown in Figure 9, in both 2001 and 2009, more than half of the bicycle-transit integrated trips were in metropolitan areas with three million people or more. However, it is statistically unclear whether transit users in larger urban areas are more or less likely to use bicycles for access/egress than urban areas of smaller sizes (Figure 10). In none of the urban size groups can data suggest significant bicycle mode share increase in transit access/egress. None of the urban size groups had a bicycle share in transit access/egress that was higher than 3 percent. 


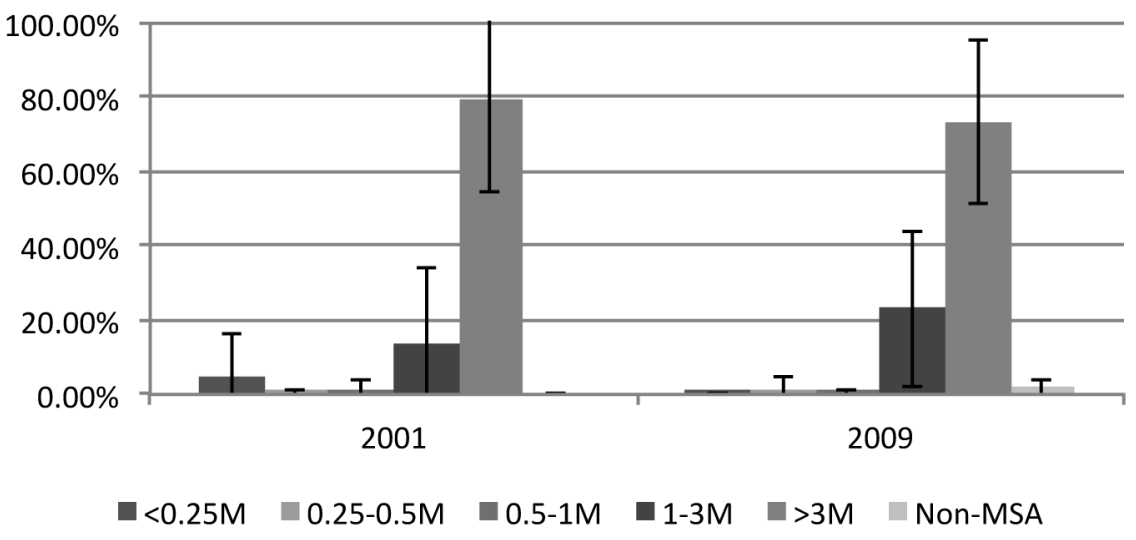

Figure 9. Shares of bicycle-transit integrated trips by MSA size

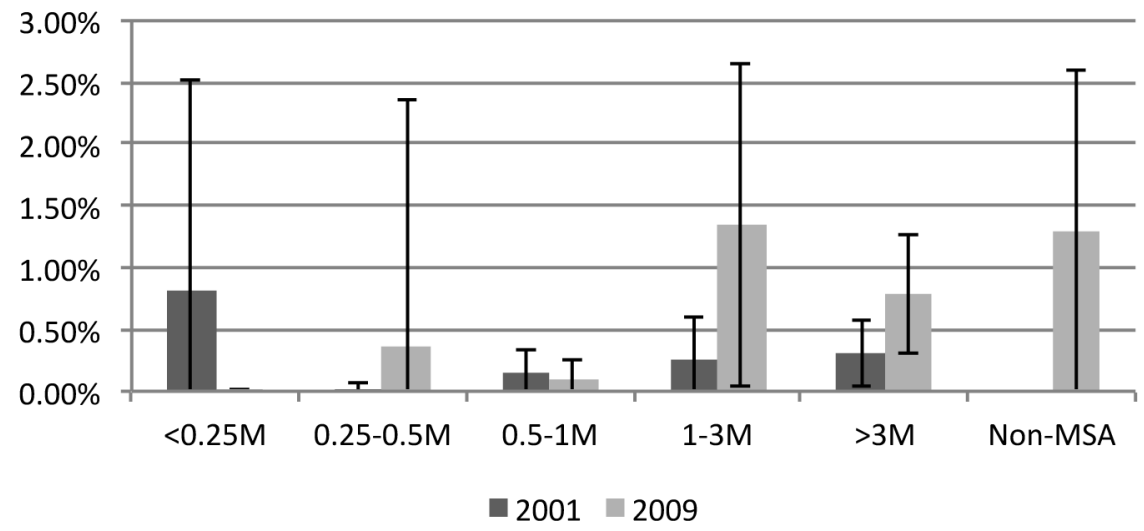

Figure 10. Bicycle's share in transit access/egress in different MSA size categories

Using community data, there also seems to be an obvious concentration of bicycletransit integrators in high-density communities (measured by population density of census tracts), as shown in Figure 11. Figure 12 shows a statistically significant increase of bicycle mode share in transit access/egress from 2001 to 2009 in tracts of the highest density category (more than 10,000 people per square mile), although no result indicates that transit riders in high density communities were more likely to use bicycles to access/egress. Anlaysis using block group-level data has similar results. 


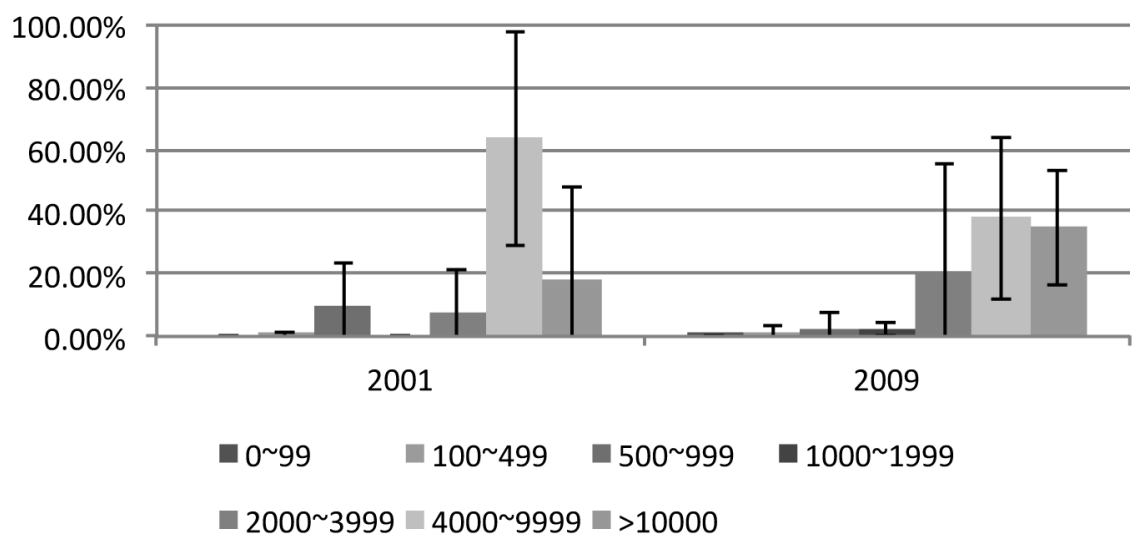

Figure 11. Shares of bicycle-transit integrated trips by tract density

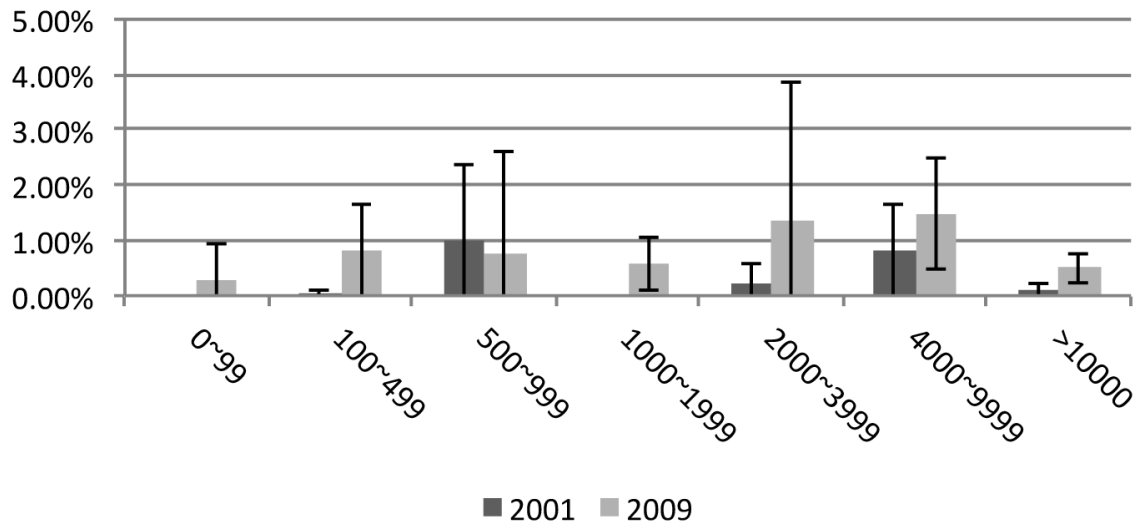

Figure 12. Bicycle's share in transit access/egress by tract density

Overall, evidence has shown a clear concentration of bicycle-transit integrated trips in large and high-density urban areas. However, such a concentration may be mainly due to the larger number of transit trips in those areas, instead of the transit users' higher likelihood of using bicycles for access/egress.

\section{Demographical Variations}

It is widely known that bicycle use is gender imbalanced in the U.S. In terms of bicycle-transit integration, between 2001 and 2009, the gender gap actually grew (Figure 13). In 2001, the number of bicycle-transit integrated trips by men was statistically no different from those by women. However, in 2009, the vast majority of integrated trips were taken by men, indicating a clear and dramatic shift in gender balance. Figure 14 explains the likely reason of such a change. From 2001 to 2009, 
bicycles' share in transit access/egress trips increased significantly for men, and remained low, if had not decreased, for female transit riders.

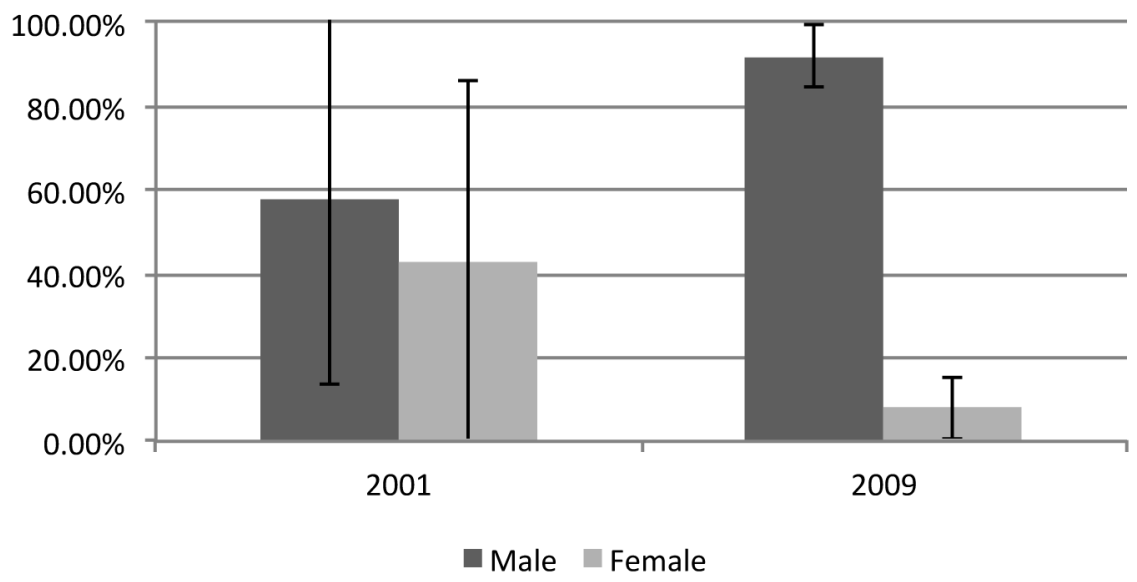

Figure 13. Gender shares of bicycle-transit integrated trips

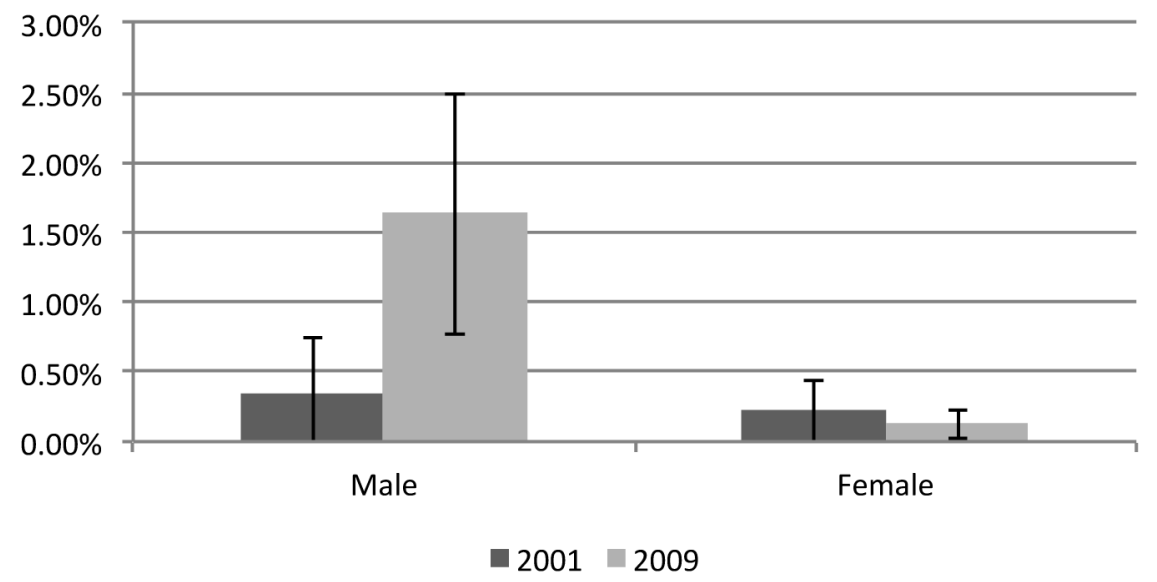

Figure 14. Bicycle's share in transit access/egress by gender

The average bicycle-transit integrator also became younger. Figure 15 suggests that the age distribution of bicycle-transit integrators became more concentrated in the age groups of 19-35 and 35-65 from 2001 to 2009. The average age of bicycletransit integrators decreased from 41 in 2001 to 36 in 2009, due to a significant increase in bicycle mode share for transit access/egress in the 19-35 age group (Figure 16). Among age groups, transit riders 65 or older were least likely to use a bicycle to access/egress in 2009. The decrease in the age of the average integrator 
also seems consistent with the increase in the distance and travel time for the average bicycle-transit integrated trip (both whole trip and access/egress).

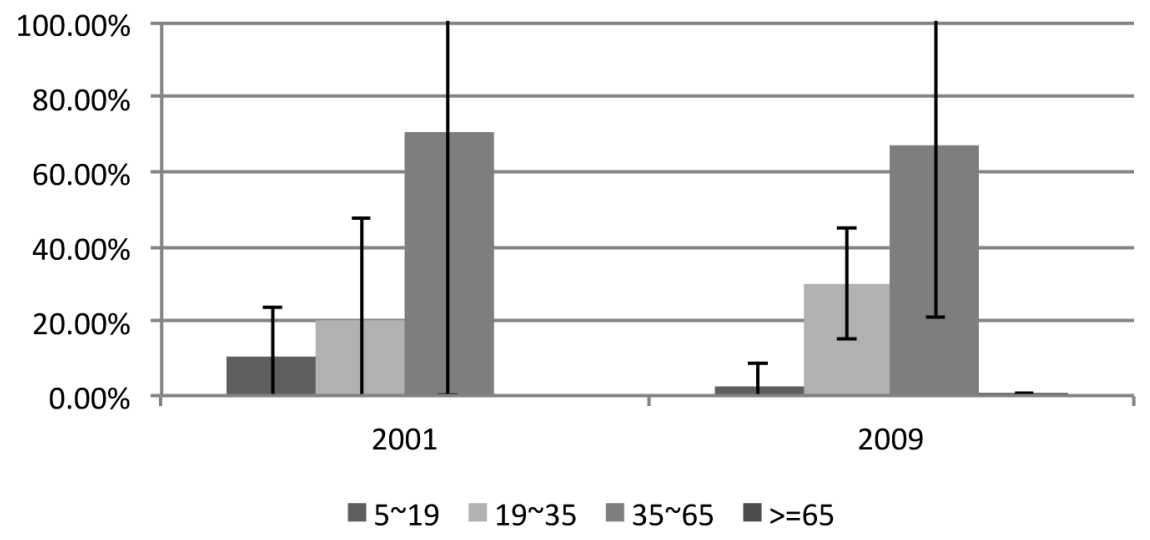

Figure 15. Age group shares of bicycle-transit integrated trips

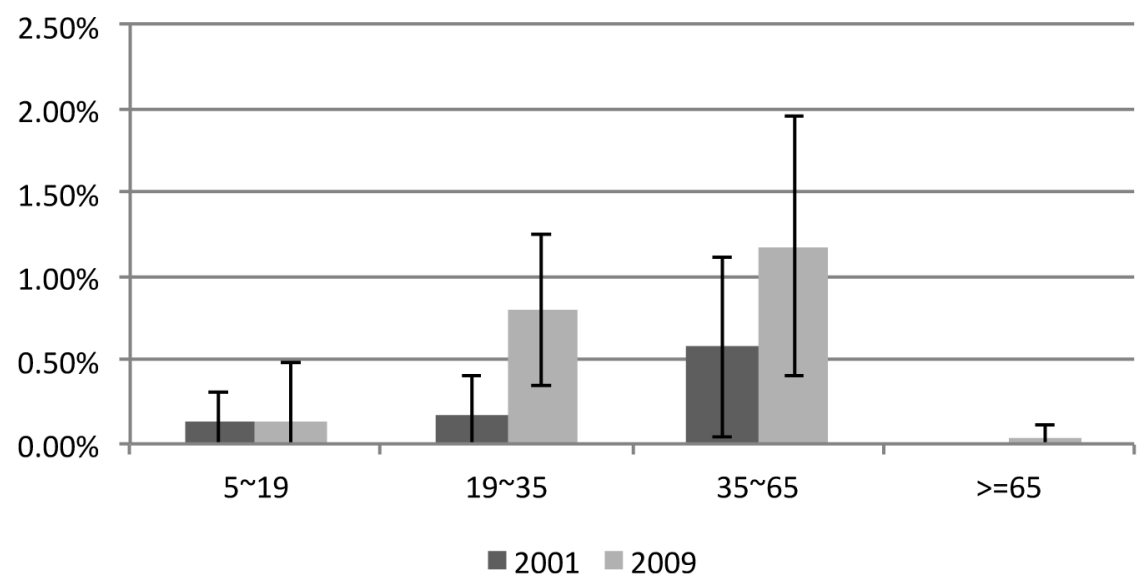

Figure 16. Bicycle's share in transit access/egress by age

White people took the majority of bicycle-transit integrated trips. The gap between white and minority integrators did not seem to shrink between 2001 and 2009 (Figure 17). This was probably due to the fact that white transit riders were more likely to use bicycles for access/egress, given that only about 40 percent of the transit riders were white (APTA 2007). None of the racial groups had a statistically significant increase in bicycle mode share in transit access/egress (Figure 18). Additionally, there was no notable pattern of bicycle-transit integration across household size or household lifecycle categories. 


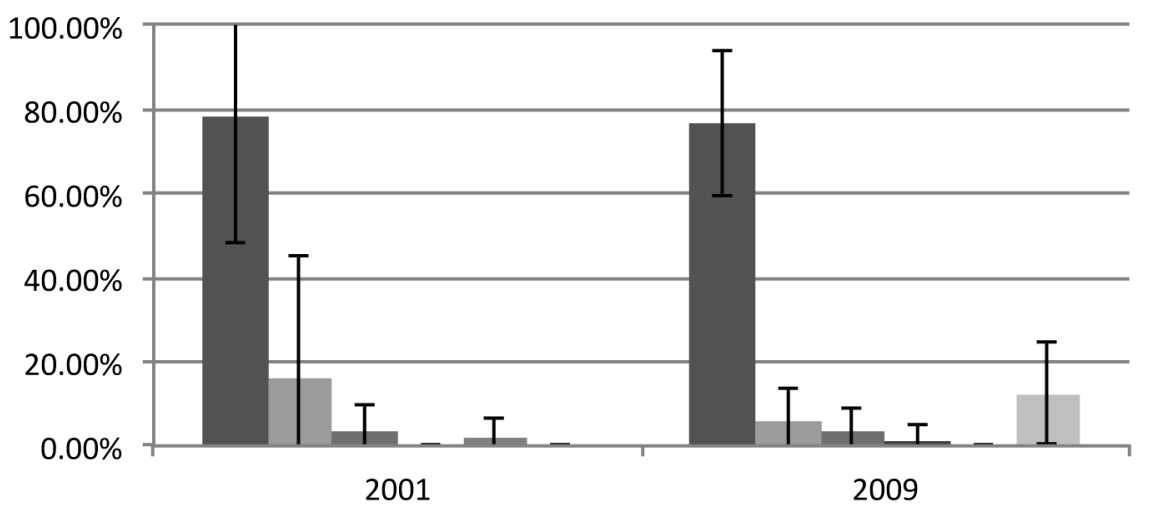

White Black Asian Pacific $\square$ Native Indian Multiracial Hispanic

Figure 17. Shares of bicycle-transit integrated trips by race

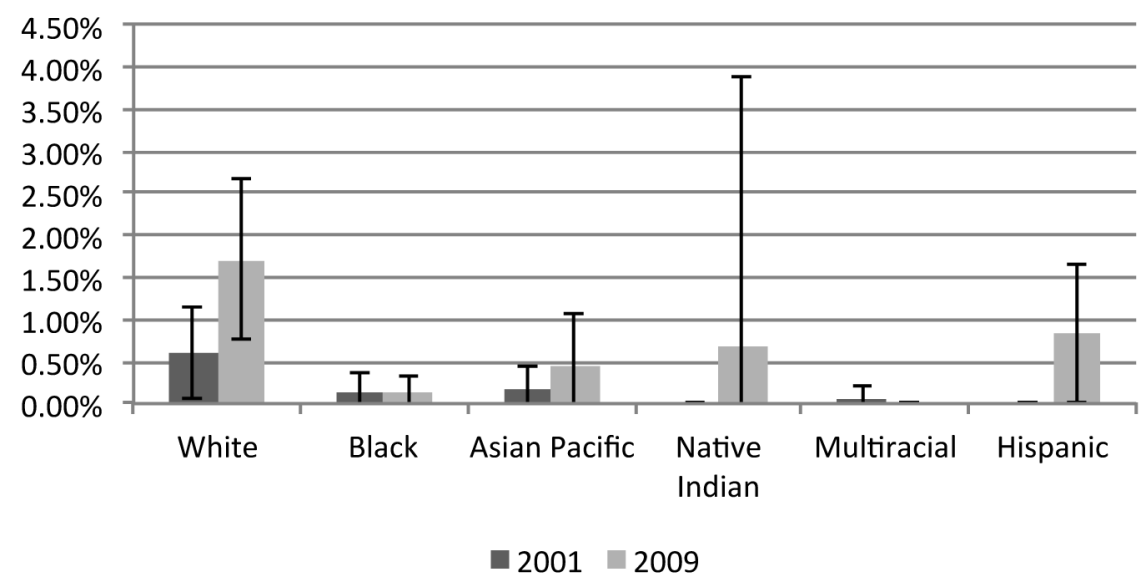

Figure 18. Bicycle's share in transit access/egress by race

\section{Socio-Economic Variations}

No notable pattern emerged from the distribution of bicycle-transit integrated trips across household income categories (Figure 19). However, Figure 20 shows a significant increase in using bicycles to access/egress transit among transit riders from households of the lowest income group (earning less than $\$ 25,000$ ). 


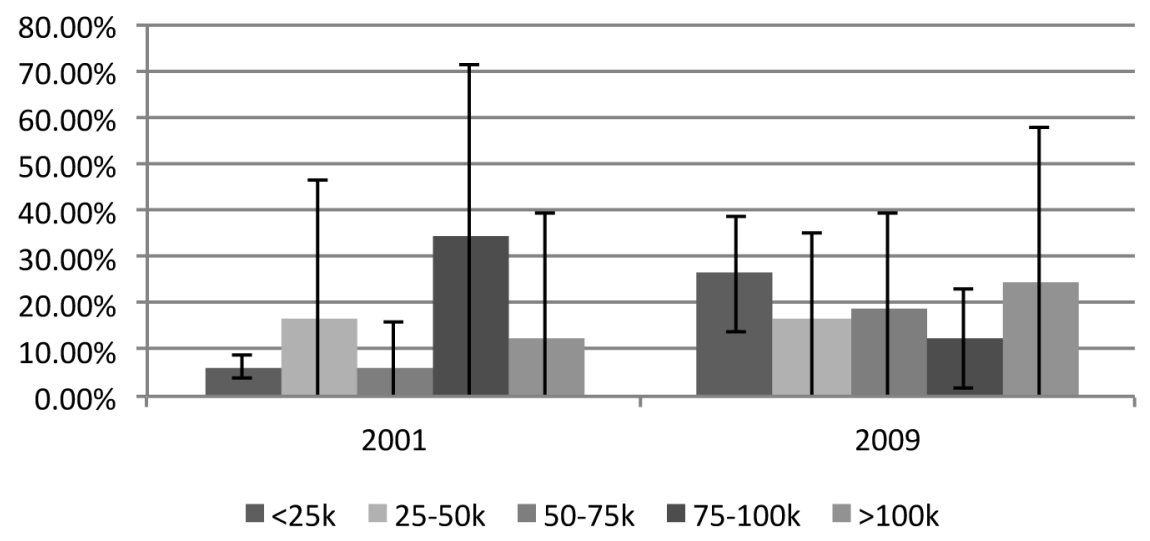

Figure 19. Shares of bicycle-transit integrated trips by income

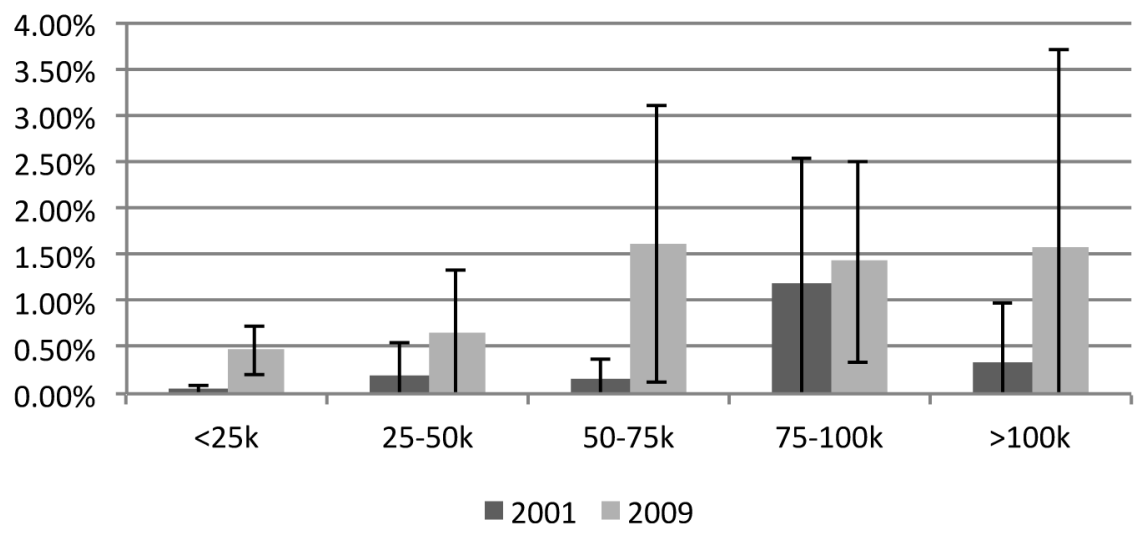

Figure 20. Bicycle's share in transit access/egress by income

Correspondingly, there was a clear rise of bicycle-transit integration among least educated people. As indicated in Figure 21, bicycle-transit integrators with graduate degrees outnumbered most other groups in 2001. By 2009, there was no longer an apparent pattern in education level. Among transit riders, the least educated group (without high school degrees) was the only group that showed a significant increase in bicycle use to access/egress (Figure 22). 


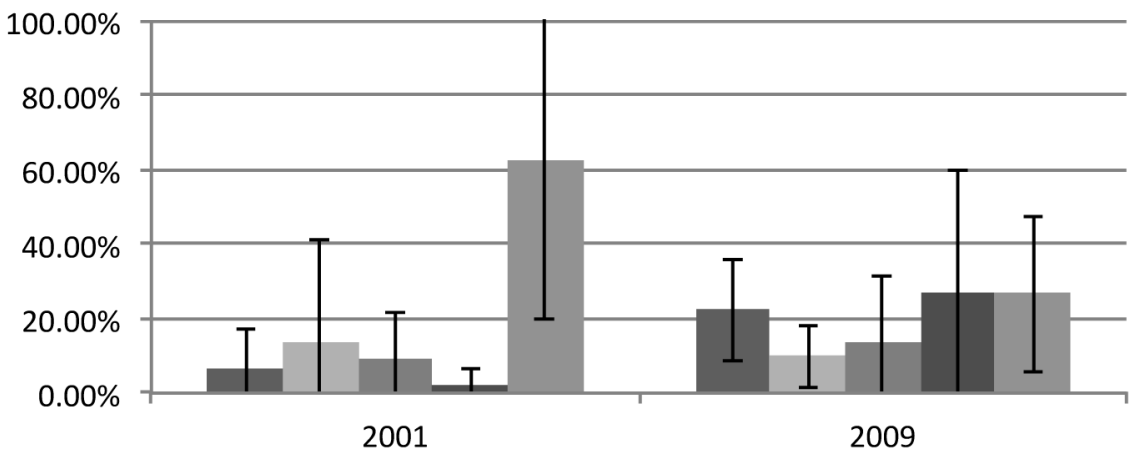

$\square$ <High School $\quad$ High School $\square$ Associate $\quad$ Bachelor $\square$ Graduate

Figure 21. Shares of bicycle-transit integrated trips by education

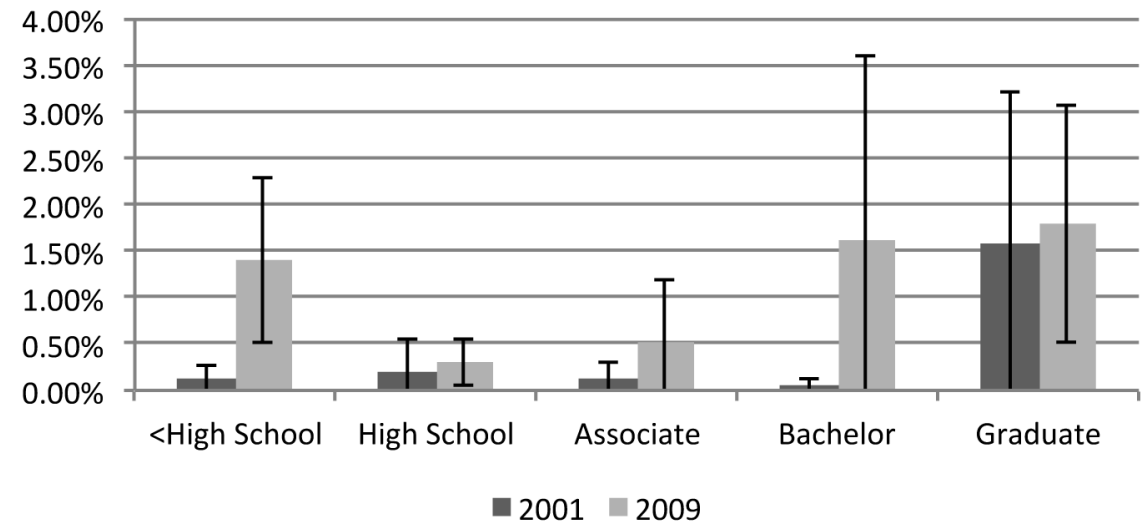

Figure 22. Bicycle's share in transit access/egress by education

Coherent patterns can also be observed in housing tenure type, unit type, and community housing tenure composition. Shown in Figure 23, in 2001 homeowners were the clear majority among bicycle-transit integrators. However, due to the significant increase in renters' use of bicycles to access/egress transit (Figure 24), such an owner-renter divide disappeared by 2009 . Similarly, relative to other communities (defined by block groups), those with high ( $>55 \%)$ proportion of rental units gained bicycle-transit integrated trips between 2001 and 2009, as shown in Figures 25 and 26. Such results can also be found when communities are defined by census tract. As a result of the significant increase in using bicycle for access/egress among transit riders living in duplex or townhouse units, Figures 27 and 28 show that the 
dominance in bicycle-transit integration by those residing in single-family houses (SFH) in 2001 disappeared by 2009.

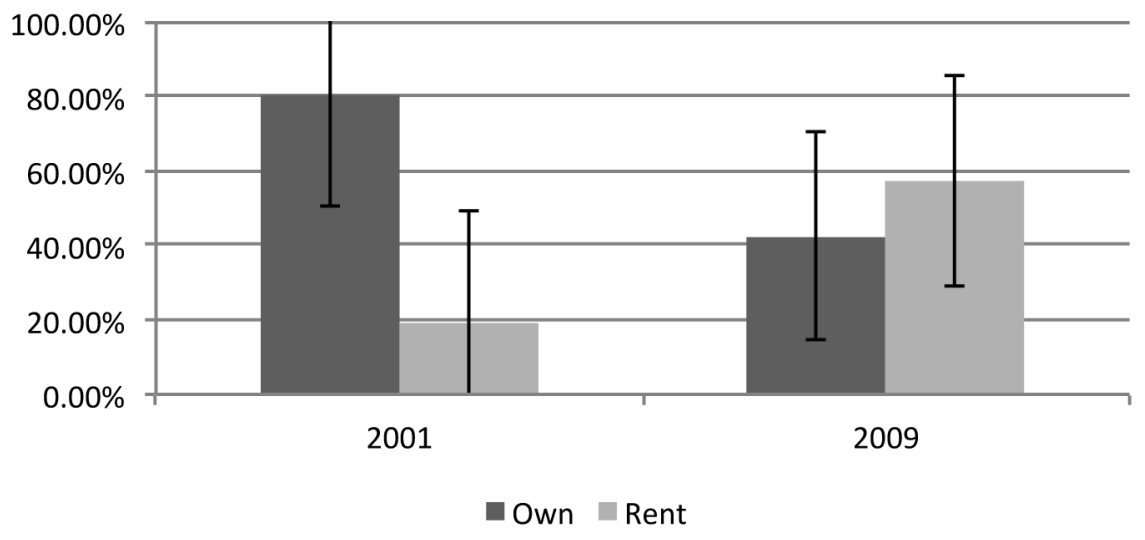

Figure 23. Shares of bicycle-transit integrated trips by housing tenure

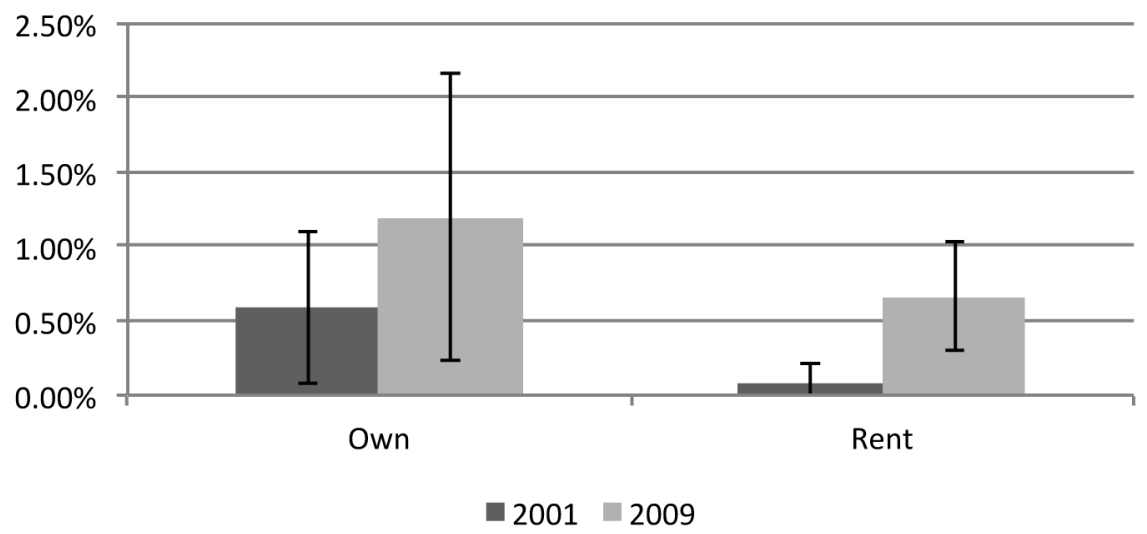

Figure 24. Bicycle's share in transit access/egress by housing tenure 


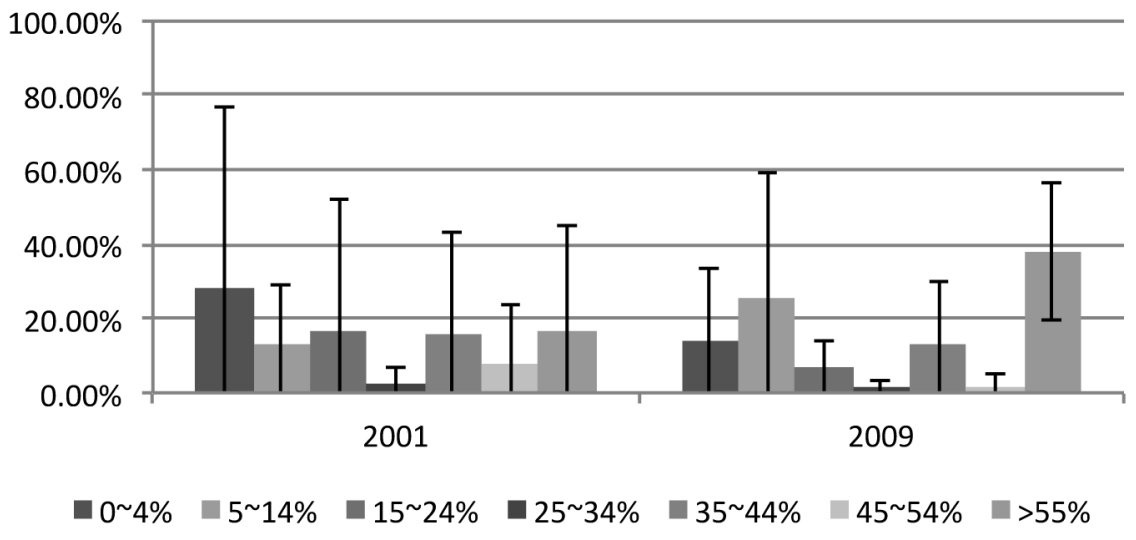

Figure 25. Shares of bicycle-transit integrated trips by block group composition

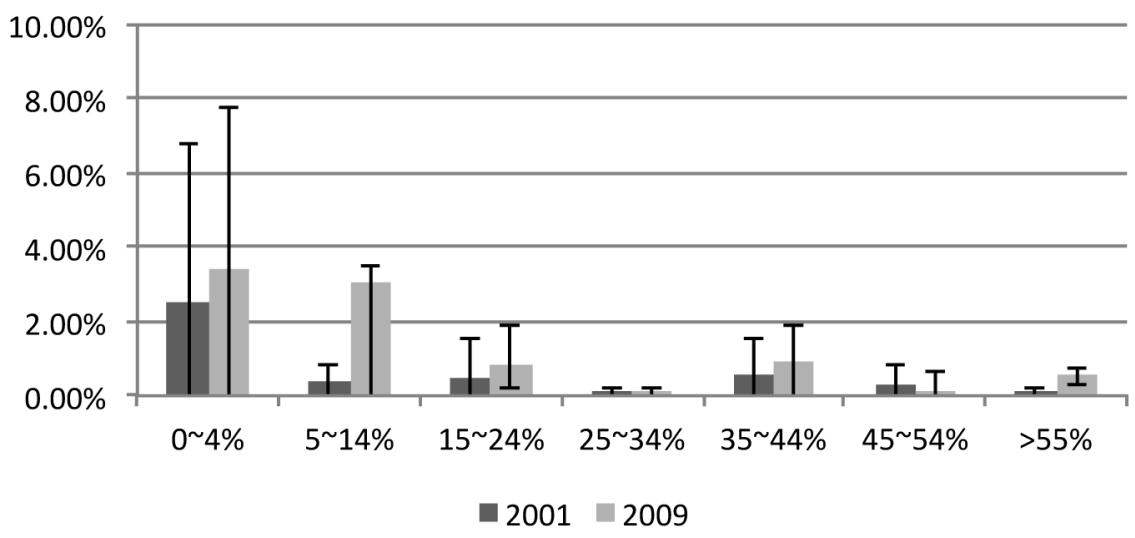

Figure 26. Bicycle's share in transit access/egress by block group composition 


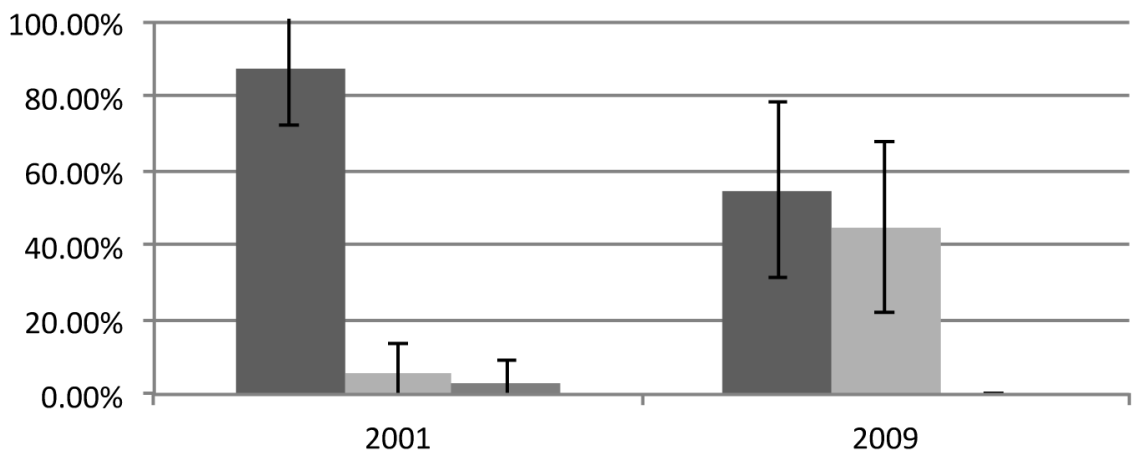

$\square$ SFH Duplex \& TH $\quad$ Apt \& Condo

Figure 27. Shares of bicycle-transit integrated trips by housing type

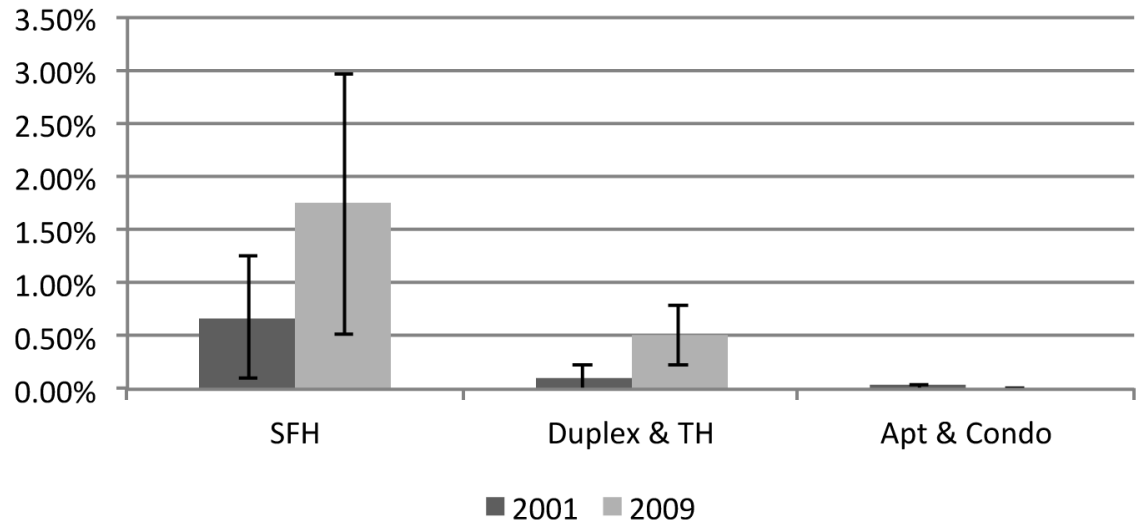

Figure 28. Bicycle's share in transit access/egress by housing type

Consistent with Martens' (2004) findings in three European countries, household vehicle ownership, a variable with potential impact on transit and bicycle usage, did not show meaningful association with the integration of bicycle and transit. Among household groups with zero, one, two, and three-plus vehicles, one could not tell from the data which group(s) had more bicycle-transit integrators. Neither could one tell which group(s) had statistically different or significant changes in bicycle mode share in transit access/egress. 


\section{Conclusion}

Sound policy making should be based on rich empirical information and robust analysis. There is a considerable gap in bicycle-transit integration research in the U.S. This study provides an early evaluation of status and trend in bicycle-transit integrated travel over the first decade of this century. It reviews NHTS statistics to provide statistically robust evidence about the characteristics of the bicycle-transit integrated trips, where the integrators were from, and to which population groups the integrators belonged.

Evidence shows that bicycle-transit integrated travel became more popular (especially among commuters) and, on average, longer in distance/time. Contrary to the European experience, evidence does not support that a faster transit mode (rail) attracts more bike access/egress trips than a slower transit mode (bus) in the U.S. Across geographical regions, more transit riders used bicycles to access/egress in the Pacific, East North Central, and Mountain regions, although the absolute number of integrated trips was higher only in the first two regions, likely due to their larger numbers of transit trips. Similarly, there remained a clear concentration of bicycle-transit integrated trips in large or high-density urban areas, but it was mainly due to the larger numbers of transit trips in those areas, instead of the transit users' higher likelihood of using bicycles.

On the socio-demographic side, bicycle-transit integrators became younger but much more male-dominant, as bicycle's share in transit access/egress trips increased significantly for men but not women. Results indicate the rise of bicycletransit integration by increasingly diversified population groups, except for a persistent racial gap. White people took the majority of bicycle-transit integrated trips, which was probably due to the fact that white transit users were more likely to use bicycles for access/egress. However, patterns by socio-economic status are different. Bicycle-transit integration was not mostly for high-income people or vehicle owners (in 2001 or 2009). Also, by 2009, bicycle-transit integration was no longer mostly for the well-educated, home owners, or those living in single family homes, because of the rise in using bicycles for transit access/egress among the bottom income group, least-educated, renters, and those living in multifamily units.

Amid certain similarities, it seems that bicycle-transit integration exhibits different patterns in the U.S. compared to Europe, with respect to, for example, urban area size/type and type of transit. The trend also implies the promise of utilizing bicycles to further enhance the accessibility of people with lower socio-economic status, who are often the captive users of transit. 
Perhaps contrary to the impression of many, although Americans choose both transit and the bicycle for a small share of their daily travel, the bicycle is not a trivial mode compared to transit. However, even with the rising attention to bicycles as a travel mode in the U.S., it seems that little resources have been allocated to bicycle compared to transit initiatives. Few transit agencies have incorporated bicycle services into their performance measures (TRB 2005). It is a mistake for policy makers and researchers to focus their attention on transit as the only important alternative mode to the automobile. Bicycle use and, as this paper suggests, the marriage between bicycle and transit, should be emphasized much more. Cities should develop bicycle parking/rental at transit stops, provisions for taking bikes aboard transit vehicles, and coordination of bike routes with transit services, as suggested by the TRB $(1994,2005)$ and Pucher and Buehler $(2012)$. Furthermore, the enlarged gender and persistent racial imbalances suggest that more information about their causes and better policy design are necessary to encourage women and minorities to take advantage of the benefits of bicycle-transit integration.

Future research should delve deeper into why these socio-demographic changes occurred and how exactly the planning and service levels of transit and bicycle transportation and other transportation policies affect bicycle-transit integration across space and over time. The NHTS is limited in its transit and bicycle sample size and cannot be relied on to study detailed travel behavior patterns and changes except the most significant ones. More modally-focused data and detailed information matching transit access and egress trips to their locations (home- and activity-end) should be collected and more in-depth analysis of bicycle-transit behavior should be conducted for better planning and policy making.

\section{Endnotes}

${ }^{1}$ It is worth noting that the statistics are calculated without differentiating between access and egress, due to the difficulty of knowing what (home-end or activity-end) each access/egress trip refers to. Still, one may suspect that the majority of bicycle-transit integration is at the home-end instead of the activity-end of the transit trip, as found in the Netherlands (Martens 2007).

${ }^{2}$ A related claim by Martens (2007) is that faster modes (rail) attract longer bike access/egress trips. The NHTS data seem to agree. In 2001, the average access/ egress time by bike to bus was 8.1 minutes, compared to 11.8 minutes to rail. The 
gap increased in 2009, when the average bike access/egress time to bus was a similar 8.3 minutes, but the time to rail was 17.2 minutes.

\section{References}

American Public Transportation Association (APTA). 2007. A Profile of Public Transportation Passenger Demographics and Travel Characteristics: Reported in OnBoard Surveys. Washington, DC: American Public Transportation Association.

Bachand-Marleau, J., J. Larsen, and A. M. El-Geneidy. 2011. Much-anticipated marriage of cycling and transit: how will it work? Transportation Research Record 2247: 109-117.

Bergman, A., J. Gliebe, and J. Strathman. 2011. Modeling access mode choice for inter-suburban commuter rail. Journal of Public Transportation 14(4): 23-42.

Brons, M., M. Givoni, and P. Rietveld. 2009. Access to railway stations and its potential in increasing rail use. Transportation Research Part 43A(2): 136-149.

Pucher, J., and R. Buehler. 2009. Integrating bicycling and public transport in North America. Journal of Public Transportation 12(3): 79-104.

Pucher, J., and R. Buehler. 2012. Integration of cycling with public transportation. Chapter 8 in Pucher, J., and R. Buehler (eds.), City Cycling. Cambridge, MA: MIT Press.

Debrezion, G., E. Pels, and P. Rietveld. 2009. Modeling the joint access mode and railway station choice. Transportation Research 45E(1): 270-283.

Federal Transit Administration (FTA). 1999. Bicycles and transit: A partnership that works. Washington, DC: Federal Transit Administration.

Givoni, M., and P. Rietveld. 2007. The access journey to the railway station and its role in passengers' satisfaction with rail travel. Transport Policy 14(5): 357-365.

Hagelin, C. A. 2005. A return on investment analysis of bikes-on-bus programs. University of South Florida: National Center for Transit Research 576-05, FDOT BD549-04.

Krizek, K. J., and E. Stonebraker. 2011. Assessing options to enhance cycling-transit integration. Transportation Research Record 2217: 162-167.

Martens, K. 2004. The bicycle as a feedering mode: experiences from three European countries. Transportation Research 9D(4): 281-294. 
Martens, K. 2007. Promoting bike-and-ride: the Dutch experience. Transportation Research 41A(4): 326-338.

Rietveld, P. 2000. The accessibility of railway stations: The role of the bicycle in the Netherlands. Transportation Research 5D(1): 71-75.

Replogle, M. 1984. The role of bicycles in public transportation access. Transportation Research Record 959: 55-62.

Replogle, M. 1992. Bicycle access to public transportation: Learning from abroad. ITE Journal December: 15-21.

Transportation Research Board (TRB). 1994. Integration of bicycles and transit. Transit Cooperative Research Program Synthesis 4, Washington, DC: Transportation Research Board.

Transportation Research Board (TRB). 2005. Integration of bicycles and transit: A synthesis of transit practice. Transit Cooperative Research Program Synthesis 62, Washington, DC: Transportation Research Board.

\section{About the Authors}

RUI WANG (ruiwang@ucla.edu) is an Assistant Professor of Urban Planning at the UCLA Luskin School of Public Affairs. His research focuses on the policy analysis of urban development and sustainability, particularly green transportation, climate change, air quality, public health, and environmental economic geography in the U.S. and/or China.

CHEN LIU is a recent graduate of the UCLA Urban and Regional Planning program with a focus in transportation planning and housing development. In Los Angeles, he is interested in promoting successful transit-oriented development, especially affordable housing in transit station areas. 